\title{
Lag time between onset of symptoms and diagnosis of endometriosis
}

\author{
Tempo transcorrido entre o início dos sintomas e o diagnóstico de endometriose
}

\author{
Tânia Mara Vieira Santos ${ }^{1}$, Ana Maria Gomes Pereira ${ }^{1}$, Reginaldo Guedes Coelho Lopes², Daniela De Batista Depes²
}

\begin{abstract}
Objective: To assess lag time between onset of symptoms and diagnosis of endometriosis in patients followed up at the Outpatients Clinic of Endometriosis and Chronic Pelvic Pain, at the Hospital do Servidor Público Estadual de São Paulo "Francisco Morato de Oliveira", from January 2003 to November 2009. Methods: In a retrospective analytical study, a total of 310 women with endometriosis confirmed by surgery and pathological examination were evaluated in the period from January 6, 2003 to November 29 , 2009. Data were gathered through revision of the follow-up visit forms at the specialized outpatients clinic and medical records. The software Epi-Info 3.3.2 was used for statistical analysis. Results: The mean lag time between onset of symptoms and confirming diagnosis of endometriosis was 46.16 months (3.84 years), ranging from 6 to 324 months. Patients aged under 20 years had a mean time until diagnosis of 2.8 years (33.6 months, range of 6 to 144 months). In patients aged $20-29$ years, it was 3.51 years ( 42.18 months, range 6-192 months). In those aged 30-40 years, the mean time was 4.14 years (49.69 months, range 6-324 months). And in women age over 40 years, it was 3.15 years (37.86 months, range 6-216 months). Conclusion: The lag time between onset of symptoms and diagnosis of endometriosis was shorter, as compared to other national and international evaluations.
\end{abstract}

Keywords: Endometriosis; Delayed diagnosis; Signs and symptoms; Pelvic pain; Chronic disease; Dyspareunia

\section{RESUMO}

Objetivo: Avaliar o tempo transcorrido entre o início dos sintomas e 0 diagnóstico de endometriose em pacientes acompanhadas no ambulatório de Endometriose e Dor Pélvica Crônica do Hospital do Servidor Público Estadual de São Paulo “Francisco Morato de Oliveira", entre janeiro de 2003 e novembro de 2009. Métodos: Em estudo analítico retrospectivo foram avaliadas 310 mulheres com endometriose confirmada cirurgicamente e por exame anatomopatológico no período de 06 de janeiro de 2003 a 29 de novembro de 2009. Os dados foram obtidos por meio de revisão das fichas de acompanhamento do ambulatório especializado e de prontuários médicos. Utilizou-se o programa Epi-Info 3.3.2 para analisar estatisticamente os resultados obtidos. Resultados: A média de tempo decorrido entre o início dos sintomas e a confirmação do diagnóstico de endometriose foi de 46,16 meses (3,84 anos), variando de 6 a 324 meses. As pacientes com menos de 20 anos de idade tiveram média de tempo decorrido até o diagnóstico de 2,8 anos (33,6 meses, variando de 6 a 144). Nas pacientes entre 20 e 29 anos, foi de 3,51 anos (42,18 meses, variando de 6 a 192). Naquelas com idade entre 30 e 40 anos, a média de tempo foi de 4,14 anos (49,69 meses, variando de 6 a 324). E, em pacientes com mais de 40 anos de idade, a média de tempo foi de 3,15 anos (37,86 meses, variando de 6 a 216). Conclusão: 0 tempo transcorrido entre o início dos sintomas e o diagnóstico de endometriose foi menor, quando comparado ao de outras avaliações nacionais e internacionais.

Descritores: Endometriose; Diagnóstico tardio; Sinais e sintomas; Dor pélvica; Doença crônica; Dispareunia

\section{INTRODUCTION}

Endometriosis is one of the gynecological conditions that affect more women at childbearing age. In the United States, it ranks third as gynecological reasons for hospitalization $^{(1)}$. It is estimated that at least 5.5 million women suffer from this disease in United States and $\mathrm{Canada}^{(2)}$. Its incidence in several studies ranges from $5 \%$ to $15 \%{ }^{(1,3-6)}$ in the childbearing age population, and from $2 \%$ to $5 \%$ in postmenopausal women, according to Patrick et al. ${ }^{(1,3)}$.

The highest endometriosis rates are observed in infertile women and range from 5\% to $50 \%$ in several studies $^{(2,7)}$. Matorras et al., between 1985 and $1991^{(8)}$,

\footnotetext{
Study carried out at Hospital do Servidor Público Estadual "Francisco Morato de Oliveira" - HSPE-FMO, São Paulo (SP), Brazil.

${ }^{1}$ Graduate Program, Instituto de Assistência Médica ao Servidor Público Estadual de São Paulo - IAMSPE, São Paulo (SP), Brazil.

2 Hospital do Servidor Público Estadual "Francisco Morato de Oliveira" - HSPE-FMO, São Paulo (SP), Brazil.

Corresponding author: Tânia Mara Vieira Santos - Rua Projetada C, 19 - Jardim Imperatriz - Zip code: 65900-000 - Imperatriz (MA), Brazil - Phone: (99) 3525-6048 - E-mail: taniamvsantos@yahoo.com.br

Received on: Oct 11, 2011 - Accepted on: Jan 15, 2012

Conflict of interest: None
} 
reported a frequency of $28.9 \%$ in 602 infertile patients submitted to laparoscopy. Dmowski et al. ${ }^{(9)}$, from 1987 to 1995 , found an incidence of $53 \%$ in patients complaining of infertility and of $67 \%$ in patients with chronic pain pelvic. The incidence of endometriosis is higher in patients with symptoms compatible with the clinical manifestations of endometriosis, such as dyspareunia, progressive dysmenorrhea, infertility and acyclic pelvic pain.

Despite the high frequency of endometriosis, some studies observed delayed diagnosis, which is made, in average, six or more years after onset of symptoms ${ }^{(2)}$. A study comparing two populations and carried out in the United Kingdom (UK) and United States (US), showed a delay in diagnosis of 12 years in the latter and of 8 years in the UK ${ }^{(10)}$. Another study conducted with 2102 members of the National Endometriosis Society of Great Britain, in 1993, demonstrated a 6.8-year delay ${ }^{(9)}$. The American study published by Dmowski et al., in 1997, estimated lag time to diagnosis as 6.4 years. In the same study, the authors demonstrated a drop in delayed diagnosis of endometriosis in the US, from 9.2 years, between 1979 and 1984, to 4.6 years, between 1990 and $1995^{(11)}$. Husby et al., in 2001, found a mean time of 5 years in delayed diagnosis of Norwegian women ${ }^{(12)}$.

The clinical manifestation of endometriosis can affect the live of patients in different manners: at work, in personal relationships and fertility. Therefore, delay in making diagnosis is disadvantageous for these patients. Moreover, in terms of healthcare expenses, loss is not only directly related to costs of exams and admissions to hospital, but also to indirect loss of work leave of several young women in their most productive period.

\section{OBJECTIVE}

To evaluate delay in making diagnosis of this condition, this study searched epidemiologic or clinical data that could be associated to delay.

\section{METHODS}

It is a retrospective analytical study evaluating the sequential medical charts of 310 women with diagnosis of endometriosis, confirmed by the pathological examination of specimen collected through surgery (laparoscopy or laparotomy). These women were seen at the Endometriosis Outpatients' Clinic, Hospital do Servidor Público Estadual de São Paulo "Francisco Morato de Oliveira" (HSPE-FMO), in the period between January 6, 2003 and November 29, 2009. In their first appointment, they answered a questionnaire that asked about age, demographic characteristics, onset of endometriosis-associated symptoms, parity, sexual activity and reproductive desire, among other data. The patients were asked about their symptoms and how they interfered in their social life.

This study was analyzed and approved by the Ethics Committee of the HSPE-FMO. Upon surgery, the lesions were observed with the purpose of classifying the stage of endometriosis according to the classification revised by the American Society for Reproductive Medicine (ASRM), in $1997^{(13)}$. The results obtained were analyzed by the statistical analysis software Epi-Info 3.3.2, and the Student $t$ test. To evaluate the lag time between onset of symptoms and diagnosis of endometriosis, the patients were selected as to duration of painful symptoms. Out of 310 patients, 48 were excluded for having acute symptoms (less than 6 months) or being asymptomatic, or due to lack of some data in the medical charts. Of the 262 women evaluated in this study, $6(2.3 \%)$ were aged under 20 years, $44(16.9 \%)$ were 20-29-years old, $161(61.7 \%)$ were 30-40-years-old, and $50(19.2 \%)$ were over 40 years. The mean age was 37.8 years (minimum 17 years and maximum 49 years). The mean age of patients with infertility was 37.4 years.

Of the total, 208 (79.7\%) were White; 51 (19.5\%) were Black and $2(0.8 \%)$ were Asian. As to schooling level, 175 (60.8) had a university degree. In terms of profession, 149 (51.6\%) were teachers. Regarding parity, $97(39 \%)$ were nulligesta. Chronic pelvic pain (persistent pelvic pain for over 6 months) was the symptom most often reported by patients.

\section{RESULTS}

Of 310 patients studied, 48 (15.4\%) were excluded for being asymptomatic or due to lack of data in their charts, remaining $262(84.5 \%)$ who were symptomatic. Chronic pelvic pain was the symptom most often reported by patients, and the main type of pain found was dysmenorrhea, referred by $217(82.8 \%)$ of 262 patients. Other symptoms reported are shown in table 1. Endometriosis lesions were more frequent in the ovaries of $191(61.6 \%)$ patients; other sites are described in table 2 .

The ASRM classification was used to assess severity of the disease ${ }^{(13)}$. This classification was obtained from 219 patients. And $50(22.8 \%)$ of them were in stage I or II, and $169(77.2 \%)$ in stage III or IV. The mean time between onset of symptoms and confirmation of diagnosis was 3.84 years (46.16 months, range of 6 to 
Table 1. Frequency of symptoms in patients with endometriosis at the Hospital do Servidor Público Estadual de São Paulo

\begin{tabular}{lcc}
\hline Symptoms & n & $\%$ \\
\hline Dysmenorrhea & 217 & 82.8 \\
Dyspareunia & 127 & 48.5 \\
Acyclic pain & 101 & 38.5 \\
Obstipation & 98 & 37.4 \\
Infertility & 71 & 27.1 \\
Pericicatricial pain & 20 & 7.6 \\
Painful evacuation & 12 & 4.6 \\
Rectal bleeding & 4 & 1.5 \\
Tenesmus & 5 & 1.9 \\
\hline
\end{tabular}

Table 2. Site of endometriosis lesions in patients at the Hospital do Servidor Público Estadual de São Paulo

\begin{tabular}{lcc}
\hline Site & $\mathbf{n}$ & $\%$ \\
\hline Ovaries & 166 & 63.4 \\
Peritoneum & 73 & 27.9 \\
Abdominal wall & 26 & 9.9 \\
Fallopian tube & 21 & 8.0 \\
Uterosacral ligament & 22 & 8.4 \\
Rectovaginal septum and retrocervical & 17 & 6.5 \\
Bowel & 11 & 4.2 \\
Bladder & 5 & 1.9 \\
Ureter & 3 & 1.1 \\
Vagina & 1 & 0.4 \\
\hline
\end{tabular}

324). Patients aged less than 20 years had a mean lag time up to diagnosis of 2.13 years (25.66 months, range of 7 to 60 ). In patients aged 20-29 years, the period was 3.51 years (42.18 months, range of 6 to 192). In those aged 30-40 years, the mean time was 4.14 years (49.69 months, range of 6 to 324). In patients over 40 years of age, the mean time was 3.15 years (37.86 months, range of 6 to 216). No significant statistical difference was found among ages regarding lag time between onset of symptoms and diagnosis of the disease. As to clinical complaints of patients and time of diagnosis of endometriosis no statistical difference was observed considering the following symptoms: pericicatricial pain, obstipation, tenesmus, rectal bleeding, hematuria and painful evacuation. However, when the symptoms reported were dysmenorrhea, dyspareunia, infertility and acyclic pain, there was significant statistical difference. When the complaint was dysmenorrhea, the patients took more time to be diagnosed as endometriosis as compared to those without this symptom (48.76 vs. 33.6 months, $\mathrm{p}=0.01435)$. When the complaint was deep dyspareunia, the mean time was longer than that of patients with other symptoms but no dyspareunia (53.8 vs. 38.9 months, $\mathrm{p}=0.01789)$. The presence of acyclic pain was associated to a shorter time for diagnosis of endometriosis (37.3 vs. 51.7 months, $\mathrm{p}=0.0139$ ). In the last three comparative analyses regarding the symptoms of dysmenorrhea, dyspareunia and acyclic pain, the statistics of Hartley test showed the populations studied were not homogeneous. When the symptom was infertility, there was statistical difference demonstrating longer lag time for diagnosis of endometriosis as compared to fertile in patients (60.1 vs. 40.9 months, $\mathrm{p}=0.006075$ ). The population samples were homogeneous in relation to fertility. As to site and severity of endometriosis, there was no statistical difference relating time of symptoms up to diagnosis of the disease.

\section{DISCUSSION}

In this study, the mean lag time between onset of symptoms and effective diagnosis of endometriosis was shorter than in other investigations. In Brazil, in 2001, Arruda et al. found a mean of 7.0 years $^{(14)}$; Halfid et al., in 1996, reported a mean of 11.7 years in the United States and 7.9 years in the United Kingdom ${ }^{(10)}$. The difference between these studies and the sample at the HSPE-FMO might be justified due to schooling level of the population evaluated, for most had a university degree. Knowledge of women about the disease and its most prevalent symptoms seems to be important.

The shorter time up to diagnosis of patients at the HSPE, when compared to other national and international studies, could also be explained by early clinical intervention. Patients have easy access to the Gynecological and Obstetric Video-assisted Endoscopy Unit of the HSPE, one of the pioneers in Brazil within the logistic structure of the Gynecology Department. The fact it is not a service provided to the public network, but only to civil servants of the State of Sao Paulo, restricts the demand of patients and directs more properly to specialized evaluations. In the past years, video-assisted laparoscopy became an effective tool in investigation of chronic pelvic pain that is intense and refractory to drug treatment, contributing to reduced delay in diagnosis of endometriosis. This fact is corroborated by observations by Dmowski et al., in the US, comparing two periods: from 1979 to 1984, when pelvic video-assisted laparoscopy was not widely available, and from 1990 to 1999. Diagnostic videoassisted laparoscopy became the main investigation method for chronic pelvic pain refractory to clinical treatment and for endometriosis. 
According to the authors, there was a significant drop in lag time between onset of symptoms and diagnosis (from 9.2 to 4.6 years) ${ }^{(9)}$. The population of female civil servants in the State of Sao Paulo has more access to this technique than patients seen at the Unified Healthcare System (SUS) [national public health system] that take much longer to receive tertiary care at a teaching hospital ${ }^{(14)}$. This fact would explain the discrepant data between the present study and that carried out by Arruda et al.

There was no statistical difference between patients aged under 20 years and those aged over 30 years, possibly because the former sample was small, representing less than $1 \%$ of the population studied. Arruda et al. demonstrated a lag time to diagnosis of 9.0 years in patients under 20 years and of 3 years in those over 30 years of age ${ }^{(14)}$. The delay in diagnosis of endometriosis in adolescents could be attributed to resistance to consider that such young patients can present this condition. In general, the lag time between menarche and onset of symptoms is short. Moreover, menstrual cramps are culturally considered normal in adolescence by patients, their families and physicians, and could be a factor that delays investigation and diagnosis of the disease ${ }^{(9,11,14,15)}$. Laufer et al. observed a high prevalence of chronic pelvic pain in adolescents, who responded to conventional medical treatment. According to some authors, endometriosis should be a presumptive diagnosis in adolescents with chronic pelvic pain ${ }^{(16,17)}$, mainly after failure of the medical treatment. Parker et al. found a prevalence of menstrual disorders in $25 \%$ of Australian adolescents. Among these disorders, $21 \%$ complained of intense pain, $26 \%$ did not attend school during the menstrual period, $33 \%$ sought medical care during menses and $26.9 \%$ considered that was "something wrong" with their periods ${ }^{(15)}$. In the present study, when the symptom reported by patients was dyspareunia or dysmenorrhea, we found a lag time for diagnosis longer than in women who denied having such symptoms. The lack of homogeneity in the sample may have contributed to this statistical finding. No other studies mentioning this association were found. Nonetheless, many studies considered dyspareunia and dysmenorrhea as "chronic pelvic pain", not differentiating the type of pain during evaluation. Longer delay in making diagnosis of endometriosis was observed in infertile patients (5 years) as compared to fertile women, which was also reported by Fernandes et al. ${ }^{(18)}$, who demonstrated a mean of 4 years for patients with infertility and of 2 years and 5 months for those with dysmenorrhea. These data contradict other studies. Arruda et al.(14) and Dmowiski et al. ${ }^{(9)}$ found differences in this specific group of women, but the lag time to diagnosis was shorter in cases of infertility. Arruda et al. ${ }^{(14)}$ reported a mean of 4.0 years in patients with infertility and of 7.4 years in patients with pelvic pain. Such discrepancy could be a consequence of an earlier investigation of the condition of infertility, even comparing women that live in the same country and in the same state ${ }^{(14)}$. The HSPE-FMO has a differentiated protocol for infertile patients. The patients included in this protocol want to get pregnant and already have some cause related infertility, such as previous tubal ligation, amenorrhea, vasectomy; patients aged over 35 years and trying to get pregnant with no success; women aged under 35 years and trying to get pregnant for over one year; history of recurrent miscarriage and late gestational losses ${ }^{(19)}$. The evaluated population (mean age of 37.4 years) seems to give priority to developing their professional career, delaying concerns about maternity. Thus, they would investigate infertility later. There are several causes for delayed diagnosis of endometriosis, including the fact that chronic pelvic pain can also be an important symptom in other clinical conditions, such as pelvic adherences, pelvic inflammatory disease, genitourinary diseases, bowel disorders, pelvic congestion and pelvic varicose veins. These conditions may coexist with endometriosis. The simultaneous occurrence of symptoms related to different organs may have contributed to a faster diagnosis of endometriosis in patients with acyclic abdominal pain, with a mean lag time shorter than in women without this symptom. Another factor that could influence in delayed diagnosis of the disease would be difficulty to manage the condition of chronic pelvic pain. The culturally accepted attitude of considering pain during menses as a normal situation, would favor delay in diagnosis. Moreover, it also contributes to delay the fact of patients having many gynecological appointments until the presumptive diagnosis of endometriosis and many others till definition of their diagnosis. Besides, the erroneous idea that complementary exams with normal results, such as transvaginal ultrasonography and serum levels of CA125, would rule out diagnosis of endometriosis, also led to delay in looking for a specialist ${ }^{(11)}$. Delay in diagnosis of endometriosis causes considerable impacts in quality of life of women who presented, for many years, unpleasant symptoms that interfered in their social, family, sexual, affective and professional life. Many times these patients are not understood by their relatives, physicians, colleagues and friends, who understimate their symptoms delaying specialized medical care. 


\section{CONCLUSION}

The present study reported a mean lag time of 3.4 years between onset of symptoms of endometriosis and its diagnosis. Such interval was shorter as compared to other national and international studies. No epidemiological factor that could have influenced this lag time was observed.

\section{REFERENCES}

1. Bellelis $P$, Dias Júnior JA, Podgaec $S$, Gonzales $M$, Baracat EC, Abrão, MS. Aspectos epidemiológicos e clínicos da endometriose pélvica: uma série de casos. Rev Assoc Med Bras. 2010;56(4):467-71.

2. McLeod BS, Retzloff MG. Epidemiology of endometriosis: an assessment of risk factors. Clin Obstet Gynecol. 2010;53(2):389-96.

3. Bellelis P, Podgaec $S$, Abrão MS. Fatores ambientais e endometriose. Rev Assoc Med Bras. 2011;57(4):456-61.

4. Barbieri RL. Etiology and epidemiology of endometriosis. Am J Obstet Gynecol. 1990;162(2):565-7.

5. Vigano P, Parazzini F, Somigliana E, Vercellini P. Endometriosis: epidemiology and a etiological factors. Best Pract Res Clin Obstet Gynaecol. 2004;18(2): 177-200.

6. Urbanetz AA, Andraus AM. Endometrose: epidemiologia e aspectos clínicos. Femina. 1999;27(3):249-55.

7. Bulletti C, Coccia ME, Battistoni $\mathrm{S}$, Borini A. Endometriosis and infertility. $\mathrm{J}$ Assit Reprod Genet. 2010;27(8):441-7.

8. Matorras R, Rodriquez F, Pijoan JI, Ramón 0, Gutierrez de Terán G, Rodriguez-
Escudero F. Epidemiology of endometriosis in infertile women. Fertil Steril. 1995;63(1):34-8.

9. Dmowski WP, Lesniewicz R, Rana N, Pepping P, Noursalehi M. Changing trends in the diagnosis of endometriosis: a comparative study of women with pelvic endometriosis presenting with chronic pelvic pain or infertility. Fertil Steril. 1997:67(2):238-43.

10. Hadfield R, Mardon H, Barlow D, Kennedy S. Delay in the diagnosis of endometriosis: a survey of women from the USA and UK. Hum Reprod. 1996; 11(4):878-80.

11. Ballard K, Lowton K, Wright J. What's the delay? A qualitative study of women's experiences of reaching a diagnosis of endometriosis. Fertil Steril. 2006;86(5):1296-301

12. Husby GK, Haugen RS, Moen MH. Diagnostic delay in women with pain and endometriosis Acta Obstet Gynecol Scand. 2003;82(7):649-53.

13. Revised American Society for Reproductive Medicine classification of endometriosis: 1996. Fertil Steril. 1997;67(5):817-21.

14. Arruda MS, Petta CA, Abrão MS, Benetti-Pinto CL. Time elapsed from onset of symptoms to diagnosis of endometriosis in a cohort study of Brazilian women. Hum Reprod. 2003;18(4):756-9.

15. Sneddon AM. The MDOT study: menstrual disorder of teenagers [abstract]. In: Program of 10th World Congress on Endometriosis. Australia; 2008. p.48.

16. Laufer MR, Sanfilippo J,Rose G. Adolescent endometriosis: diagnosis and treatment approaches. J Pediatr Adolesc Gynecol. 2003;16(3 Suppl):S3-11.

17. Stratton P. The tangled web of reasons for the delay in diagnosis of endometriosis in women with chronic pelvic pain: will the suffering end? Fertil Steril. 2006;86(5):1302-4.

18. Fernandes AM, Silvia MS, Armani BO, Sollero CA, Yamada EM, Quintino A, et al. Demora para diagnosticar a endometriose pélvica em serviço público de ginecologia em Campinas. Rev Cienc Med (Campinas). 2003;12(2):123-9.

19. Lopes RG, Baracat FF, Lippi UG. Ginecologia: manual de normas e condutas. 2a ed. Rio de Janeiro: EPUB; 2009. p.131-60. 